\title{
The clinical and biological significance of STAT1 in esophageal squamous cell carcinoma
}

\author{
Ying Zhang ${ }^{1,2}$, Ommoleila Molavi ${ }^{2}$, Min Su ${ }^{1 *}$ and Raymond Lai ${ }^{2,3,4,5^{*}}$
}

\begin{abstract}
Background: Loss of STAT1 (Signal Transducer and Activator of Transcription-1) has been implicated in the pathobiology of a number of cancer types. Nonetheless, the biological and clinical significance of STAT1 in esophageal squamous cell carcinomas (ESCC) has not been comprehensively studied.
\end{abstract}

Methods: Using immunohistochemistry, we detected the STAT1 expression in a cohort of ESCC patients; In-vitro experiments, we used enforced gene transfection of STAT1C into two STAT1- weak/negative ESCC cell lines and siRNA knockdown of STAT1 in two STAT1-strong ESCC cell lines to detect STAT1 function in ESCC.

Results: We found that the expression of STAT1 was heterogeneous in ESCC, with 64 (49.0\%) strongly positive cases, 59 (45.0\%) weakly positive cases and $8(6.1 \%)$ negative cases. STAT1 expression inversely correlated with the depth of tumor invasion and tumor size ( $p=0.047$ and $p=0.029$, respectively, Chi square). Furthermore, patients with STAT1-strong/weak tumors had a significantly longer survival compared to those with STAT1-negative tumors (33.6 months versus 13.1 months, $p=0.019)$. In patients carrying tumors of aggressive cytology $(n=50)$, those with STAT1strong tumors survived significantly longer than those with STAT1-weak/negative tumors (34.6 months versus 20.5 months, $\mathrm{p}=0.011$ ). Our in-vitro experiments revealed that STAT1 is proapoptotic and inhibitory to cell-cycle progression and colony formation. Lastly, we found evidence that STAT1 signaling in ESCC cells down-regulated the expression and/or activity of NF-KB and STAT3, both of which are known to have oncogenic potential.

Conclusion: To conclude, our findings suggest that STAT1 is a tumor suppressor in ESCC. LOSS of STAT1, which is frequent in ESCC, contributes to the pathogenesis of these tumors.

Keywords: STAT1, Esophageal squamous cell carcinoma, Prognosis, NF-kB, STAT3

\section{Background}

Members of the STAT protein family are known to regulate various cellular processes involved in oncogenesis, including cell cycle progression, apoptosis, angiogenesis, invasion, metastasis, and evasion of the immune system [1]. STAT1, as the first discovered member of the STAT family, serves as the principal mediator of both type I and type II interferon activation [2]. Recent studies have revealed that the expression of STAT1 is frequently lost in various types of human cancer such as breast cancer, head and neck cancer, multiple myeloma and leukemia [3]. Furthermore, it has been reported that STAT1 can inhibit the growth of benign

\footnotetext{
* Correspondence: minsu@stu.edu.cn; rlai@ualberta.ca

'Department of Pathology, Shantou University Medical College, 22 Xinling

Road, Shantou 515031, Guangdong Province, China

'Department of Laboratory Medicine and Pathology, University of Alberta,

Edmonton, Alberta, Canada

Full list of author information is available at the end of the article
}

and neoplastic cells by regulating the transcription and expression of a host of pro-apoptotic and anti-proliferative genes, such as caspases, BCL-xL and p21 waf1 [4]. Overall, these observations suggest that STAT1 carries tumor suppressor functions.

Esophageal cancer is one of the leading causes of cancer-related deaths worldwide [5]. This type of cancer is known to be highly frequent in specific geographic regions in China, such as the Chaoshan area. Specifically, the annual average age-standardized incidence rate of esophageal cancer in Chaoshan is $74.5 / 100,000$ people [6], as compared to $7.0 / 100,000$ people worldwide. This finding suggests that various genetic and/or environmental factors may predispose the population in Chaoshan to esophageal cancer. Interestingly, esophageal cancer found in Chaoshan predominantly carries the histology of squamous cell carcinoma, in contrast with that in the Western 
world which predominantly carries the histology of adenocarcinoma [7]. The pathogenesis of ESCC is incompletely understood. The overall survival of these patients remains to be relatively poor, with the overall 5-year survival rate being approximately $15 \%$ [8]. In one previous study, it was found that $\gamma$-interferon can induce significant apoptosis in ESCC cell lines and this process correlates with STAT1 activation [9]. In parallel with this observation, it was reported that the EGF-STAT1 signaling pathway, which is active in normal esophageal epithelial cells, is lost in a considerable fraction of esophageal cancer; furthermore, loss of EGF-STAT1 signaling was found to correlate with a worse clinical outcome [10]. Nevertheless, the clinical and biological significance of STAT1 in ESCC has never been directly or comprehensively examined.

In the present study, we tested our hypothesis that STAT1 is a tumor suppressor in ESCC. First, using immunohistochemistry and Western blots, we comprehensively evaluated the expression of STAT1 in a large cohort of ESCC harvested from patients from Chaoshan. Second, we evaluated the clinical and prognostic significance of STAT1 in ESCC. Third, we used an in-vitro model to assess the biological functions of STAT1 in ESCC cells.

\section{Methods}

\section{ESCC tumor samples and cell lines}

We collected 131 consecutive ESCC tumors at the Shantou Tumor Hospital between 2005 and 2012. All patients underwent potentially curative surgery without preoperative chemotherapy or radiotherapy. In this cohort, 98 were men and 33 were women; the age was $36-78$ years, with a median of 57 years. Follow-up data was available for 74 patients; most $(58,78.4 \%)$ died during the follow-up period (median, 31.4 months). The study was approved by the ethical review committees of the Medical College of Shantou University. All participants involved in our study were given written informed consents.

Four ESCC cell lines (EC1, EC109, KYESE150 and KYSE510) and 4 human esophageal immortalized epithelial cell lines (SHEE, NE2, NE3, and NE6) were included in this study. The ESCC cell lines were gifts from Shantou University Medical College and esophageal immortalized epithelial cell lines were gifts from University of Hong Kong. All of them were cultured in DMEM supplemented with $10 \%$ fetal bovine serum at $37^{\circ} \mathrm{C}$ under $5 \% \mathrm{CO}_{2}$.

Antibodies, subcellular fractionation and western blotting Western blot analysis was performed using standard techniques as previously described [11]. The following antibodies were employed: anti-STAT1 (1:1000) and anti-pSTAT1 (Tyr-701) (1:1000), anti-FLAG (1:1000), anti-caspase 3 (1:1000), anti-survivin (1:1000), anti- BCL-2 (1:1000) antip21 (1:1000) and anti-cyclin D1 (1:1000), all of which were purchased from Cell Signaling (Danvers, MA, USA). Anti-
STAT3 (1:1000), anti-p-STAT3 (Tyr-705) (1:1000), antiBCL-xL (1:1000) and anti-ß-actin (1:1000) were obtained from Santa Cruz Biotechnology (Santa Cruz, CA, USA). Densitometric analysis was performed using the Image analysis system (Bethesda, WA, USA); the values for the STAT1 bands were normalized to those of the $\beta$-actin bands.

\section{Immunohistochemistry}

Immunohistochemistry to detect STAT1 expression was performed using a method similar to that described previously [12]. Using the same antibody we employed for our Western blot studies, we performed immunohistochemistry and the staining results were independently evaluated by two pathologists who were blinded to the clinical data. For each case, the percentages of cells showing negative, weak or strong cytoplasmic STAT1 staining was recorded. Using our scoring system (the sum of \% of cells strongly positive for STAT1 x 3 and \% of cells weakly positive for STAT1 x 1), we determined that a cut-off of 80 points allowed us to achieve the lowest p-values in our statistical analysis. Thus, tumors with a score of $<80$ point were classified as STAT1-weak whereas those with a score of $\geq 80$ points were classified as STAT1-strong.

\section{Co-immunoprecipitation}

A total of $2 \mu \mathrm{g}$ of anti-STAT3 monoclonal antibody (Santa Cruz Biotechnology) was added to $500 \mu \mathrm{g}$ of protein lysate isolated in cell lytic M (Sigma Aldrich, St Louis, MD, USA) and the samples were rotated overnight at $4^{\circ} \mathrm{C}$. Subsequently, $30 \mu \mathrm{l}$ of protein G Plus/A beads (Emdmillipore, Billerica, MA, USA) was added to the samples and rocked overnight at $4^{\circ} \mathrm{C}$. The beads were then washed 3 times with cold phosphate-buffered saline followed by the final wash using cold cell lysis buffer. Western blot analysis was then performed using standard techniques as previously described [11].

\section{Plasmids, cell transfection and NF-KB transcriptional activity}

FLAG-tagged STAT1C cloned into the backbone of pcDNA3.1 was a gift from Dr. Ouchi (University of New York) [13]. For each experiment, $1 \times 10^{6}$ ESCC cells were transiently transfected with $10 \mu \mathrm{g}$ of STAT1C vector or the pcDNA3.1 empty vector (Invitrogen, Burlington, Ontario, CA) in 6-well plates using the lipofectamine 2000 reagent (Invitrogen) as per manufacturer's suggested protocol. The NF- $\mathrm{B}$ transcriptional activity analyses were performed as previously described [12].

\section{Short interfering RNA and gene transfection}

$5 \times 10^{6}$ ESCC cells in $2 \mathrm{ml}$ of culture medium were transfected with 100 pmol of SMARTpool-designed siRNA against STAT1 obtained from Dharmacon (Lafoyetle, CO, 
USA). Cells transfected with scrambled siRNA (Dharmacon) were used as the negative controls. Gene transfection was performed by using lipofectamine RNAiMax (Invitrogen) as per manufacturer's suggested protocol.

\section{Cell-cycle analysis by flow cytometry and assessment of cell growth}

Flow cytometry analyses were performed at the University of Alberta flow cytometry core facility as previously described [12]. All experiments were performed in triplicates.

To assess cell growth, ESCC cells were plated at a density of $20,000 / \mathrm{ml}$ of culture medium. Cell count, done daily for 4 days, was performed using trypan blue staining (Sigma-Aldrich) according to the manufacturer's protocol. Triplicate experiments were performed.

\section{Colony formation assay}

After STAT1C transfection, 500 cells/well were plated in six-well plates and incubated 10 days at $37^{\circ} \mathrm{C}$. The cells were fixed with $4 \%$ buffered formalin for $15 \mathrm{~min}$ and then stained with $1 \%$ crystal violet (Sigma Aldrich) for $30 \mathrm{~min}$. The plates were gently washed with PBS and dried before microscopic evaluation. Cell clusters with $>30$ cells were considered as a colony.

\section{Quantitative RT-PCR}

Using the RNeasy Mini Kit (QINGEN, Valencia, CA, USA), total cellular RNA was extracted from cells following the manufacture's protocol. Reverse transcription was performed using $1 \mu \mathrm{g}$ of total RNA and superscript reverse transcriptase obtained from Invitrogen. Quantitative PCR was performed using SYBR green (Invitrogen), and the primer sets for STAT1 and GAPDH were purchased from Invitrogen. For both primer sets, the PCR conditions were as follows: $95^{\circ} \mathrm{C}$ for 10 minutes, followed by 40 cycles of $95^{\circ} \mathrm{C}$ for 15 seconds and $60^{\circ} \mathrm{C}$ for 1 minute. Samples were processed on an ABI 9700 HT system (Applied Biosystems Inc., Foster City, CA). Results were examined using the SDS 2.2 software, and the relative expression levels of STAT1 were calculated by normalizing with those of GAPDH.

\section{Cell invasion assay}

The invasion assays were done using basement membrane (Cell biolabs, NY). The ESCC cell treat with STAT1C or empty vector were prepared before the experiment. Then, $5 \times 10^{5}$ cells in $300 \mu \mathrm{L}$ serum-free DMEM supplemented were seeded into the upper part of each chamber, whereas the lower compartments were filled with $500 \mu \mathrm{l}$ of $10 \%$ fetal bovine serum media. Following incubation for 48 hours at $37^{\circ} \mathrm{C}$, the insert was incubated in the cell detachment solution. The invasiveness was determined by fluorescence measurement, and the extent of invasion was expressed as an average number of cells per microscopic field.

\section{Statistical analysis}

Statistical analysis was performed with the SPSS15.0 software. The association between expression of STAT1 and survival was analyzed using the Kaplan-Meier's. The correlation between STAT1 and other clinical parameters was evaluated using Chi square or Student's $t$ test. A value of $\mathrm{p}<0.05$ was considered as statistically significant.

\section{Results \\ Expression of STAT1 in esophageal squamous cell carcinoma (ESCC)}

To survey the expression of STAT1 expression in our cohort of ESCC, we performed immunohistochemistry (IHC) applied to paraffin-embedded tissues. STAT1 immunoreactivity, assessed based on the presence of cytoplasmic staining, was detectable in the vast majority of cases (123 of 131, 93.8\%). The staining intensity was categorized as strong $(\mathrm{n}=64,49.0 \%)$ or weak $(\mathrm{n}=59$, 45.0\%) (Figure 1). Of these 123 STAT1-positive tumors, nuclear staining was detectable in $58(47.2 \%)$ cases. The remaining $8(6.1 \%)$ cases had no detectable cytoplasmic or nuclear STAT1 expression. Benign esophageal epithelial cells had relatively strong STAT1 immunostaining in both their nuclei and cytoplasm (illustrated in Figures 1A e and 1A f).

We then validated the IHC findings using Western blots. Of the 131 cases studied by IHC, fresh tumor tissues were available in 57 cases. STAT1 at $91 \mathrm{kd}$ was detectable in all tumors examined, although the intensity was variable, as illustrated in Figure 1B. Densitometry analysis was performed to generate a value for the STAT1 band derived from each of the 57 cases. Based on these values, the 57 cases were categorized as STAT1-high $(\mathrm{n}=23,40.4 \%)$ or STAT1-low $(\mathrm{n}=34$, 59.6\%). As shown in Table 1, data generated from the IHC and Western blot studies significantly correlate with each other $(\mathrm{p}=0.0003$, Fisher exact test). Specifically, $19(33.3 \%)$ cases showing strong IHC for STAT1 were STAT1-high by Western blots; 23 (40.4\%) cases showing weak/negative IHC for STAT1 were STAT1-low by western blots.

\section{The clinical significance of STAT1 expression in ESCC}

We then assessed if STAT1 expression detectable by IHC correlated with various and clinical and pathologic parameters, including gender, location and size of the tumor, lymph node metastasis, histologic grade, depth of tumor invasion and the overall clinical stage. As summarized in Table 2, we found that STAT1 expression inversely correlated with the depth of tumor invasion and 

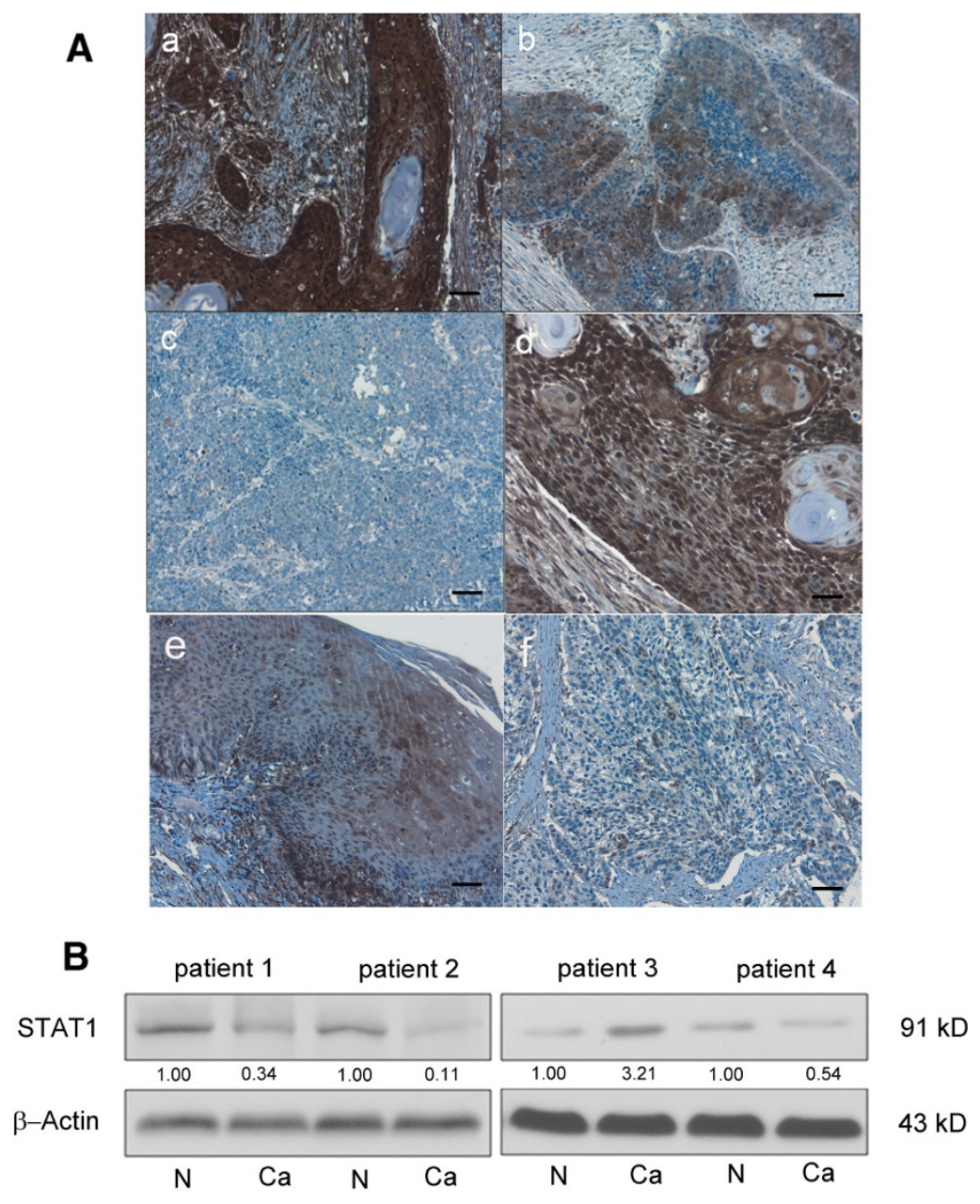

C
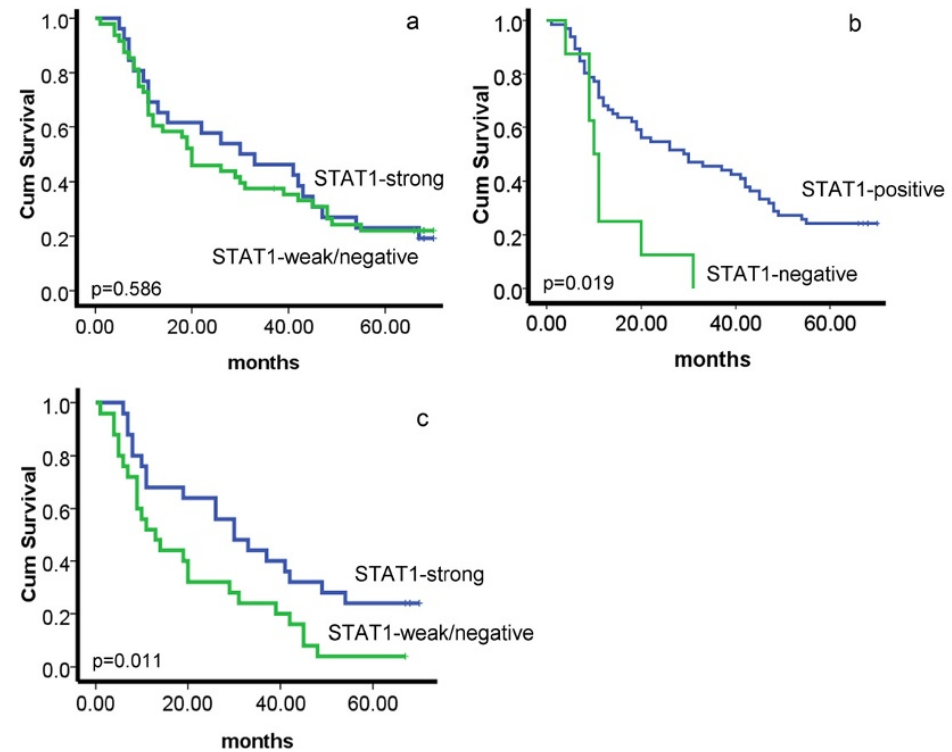

Figure 1 (See legend on next page.) 
(See figure on previous page.)

Figure 1 Heterogeneous STAT1 expression in ESCC. (A) By immunohistochemistry applied to formalin-fixed paraffin-embedded tissues, variable levels of STAT1 were detectable in most ESCC tumors examined. The staining was predominantly cytoplasmic. Based on the staining intensity, tumors in our cohort was categorized into STAT1-strong (a) or STAT1-weak (b); 8 cases were STAT1-negative (c) (IHC stain, scale bar, $20 \mu \mathrm{m})$. Nuclear staining of STAT1 was detected in some ESCC cases (d) (IHC stain, scale bar, 50 um). The normal epithelium (e) from a STAT1-weak tumor (shown in $\mathbf{f}$ ) was also illustrated (scale bar, 20 mm). (B) By Western blots, STAT1 expression in ESCC tumors was examined. Compared to the benign esophageal tissue harvested at the surgical margins in the same specimens (labeled as N) cancerous tissues (labeled as Ca) often expressed a lower level of STAT1. Thus, tumors from patient \#1, 2 and 4 were categorized as STAT1-low. A small subset of tumors (e.g. that from patient \#3) were categorized as STAT1-high, since the expression of STAT1 in the cancerous tissue was appreciably higher than that of the benign esophageal tissues in the same specimen. (C) By Kaplan-Meier analysis, we found no significant correlation between overall survival and the expression level of STAT1, when the two groups were defined as STAT1-strong and STAT1-weak/negative (a). In contrast, we found a significant correlation between overall survival and the expression level of STAT1 protein levels when the two groups were defined as STAT1-positive or STAT1-negative (b). With the subset of patients carrying poorly or intermediate-differentiated tumors, those with STAT1-strong tumors survived significantly longer than those with STAT1-weak/negative tumors (c).

tumor size $(\mathrm{p}=0.047$ and $\mathrm{p}=0.029$, respectively, Chi square). Cases with strong STAT1 expression also showed a trend toward a higher degree of histologic differentiation ( $\mathrm{p}=0.074$, Chi square). Compared to the poorly differentiated tumors $(\mathrm{n}=12)$, well- or intermediate-differentiated tumors $(n=129)$ significantly correlated with strong STAT1 immunostaining ( $\mathrm{p}=0.032$, Fisher square). Nuclear expression of STAT1 did not show significant correlation with any of these clinicopathologic parameters.

Clinical follow-up data was available for 74 of the 131 patients included in this study (median follow-up, 31.4 months; range 1-70 months). The survival data was analyzed using Kaplan-Meier's. Approximately half of these tumors (34 of 74, 45.9\%) were assessed strongly positive for STAT1 by IHC, and 40 (54.0\%) were assessed weak/negative. The overall survival of patients with STAT1-strong tumors was found to be similar to that of patients with STAT1-weak/negative tumors (35.9 months versus 31.1 months, $\mathrm{p}>0.05$ ). In contrast, patients with STAT1-strong/weak tumors $(n=66)$ had a significantly longer survival compared to those with STAT1-negative tumors $(\mathrm{n}=8)$ (33.6 months versus 13.1 months, $\mathrm{p}=0.019)$. Furthermore, of the 74 patients for whom follow-up data was available, 50 carried poorly or intermediate-differentiated tumors. In this sub-group, patients with STAT1-strong tumors survived significantly longer than those with STAT1-weak/negative tumors (34.6 months versus 20.5 months, $\mathrm{p}=0.011$ ).

Table 1 STAT1 expression in ESCC: significant correlation between IHC and Western blot data

\begin{tabular}{|c|c|c|c|c|}
\hline \multirow[t]{2}{*}{$\begin{array}{l}\text { STAT1 expression } \\
\text { level by IHC }\end{array}$} & \multicolumn{3}{|c|}{$\begin{array}{l}\text { STAT1 expression level } \\
\text { by western-blot }\end{array}$} & \\
\hline & High & Low & Total & \\
\hline Strong & 19 & 11 & 30 & \\
\hline Weak & 4 & 23 & 27 & \\
\hline negative & 0 & 0 & 0 & \\
\hline Total* & 23 & 34 & 57 & $P=0.0003$ \\
\hline
\end{tabular}

*all cases in this cohort were positive for STAT1.
Nuclear STAT1 expression again did not significantly correlate with the overall survival in this sub-group.

\section{Roles of STAT1 in ESCC cell lines STAT1 expression in ESCC cell lines}

In light of the clinical significance of STAT1 in ESCC, we examined its roles in ESCC using an in-vitro model. The expression of STAT1 in a cohort of human ESCC cell lines (EC1, EC109, KYSE150 and KYSE510) as well as a cohort of human immortalized esophageal epithelial cell lines (SHEE, NE2, NE3 and NE6) was examined using Western blots. MCF7, an estrogen receptor-positive breast cancer cell line, served as the positive control for STAT1. As shown in Figure 2, we were able to detect STAT1 in 6 of these 8 cell lines; EC109 and SHEE were STAT1-negative. In the 6 STAT1-positive cell lines, EC1 and KYSE150 expressed STAT1 relatively weakly, whereas KYSE510, NE2, NE3 and NE6 expressed STAT1 relatively strongly. The expression of the phosphorylated/activated form of STAT1 (p-STAT1) in these cell lines was also assessed in these 8 cell lines. Except for EC1, all STAT1-positive cell lines expressed p-STAT1, although all of the immortalized cell lines (including NE2, NE3 and NE6) expressed pSTAT1 relatively weakly.

\section{The biological impact of STAT1C in ESCC cell lines}

Using the ESCC cell lines, we then performed specific in-vitro studies. First, we examined the biological impact of enforced expression of the constitutively active form of STAT1 (i.e. STAT1C) in ESCC. To this end, EC1 and EC109, both of which were STAT1-weak/negative cell lines, were employed and they were subjected to gene transfection of STAT1C. As shown in Figure 3A, the expression of STAT1C was confirmed by the high intensity of the total STAT1 band and the strong expression of FLAG, which was tagged to the STAT1C construct. These changes correlated with a significant decrease in the number of viable cells, as assessed using the trypan blue exclusion assay (Figure 3B). As shown in Figure $3 \mathrm{C}$ and D, STAT1C transfection in EC1 and EC109 cells led to a significant decrease in colony 
Table 2 Correlations between STAT1 expression and various clinicopathologic parameters in ESCC

\begin{tabular}{|c|c|c|c|c|c|}
\hline \multirow[t]{2}{*}{ Parameter } & & \multirow{2}{*}{$\begin{array}{l}\text { Case } \\
\text { number }\end{array}$} & \multicolumn{2}{|c|}{ STAT1 expression by IHC } & \multirow[t]{2}{*}{ Result } \\
\hline & & & Negative/Weak & Strong & \\
\hline \multirow[t]{2}{*}{ Age } & $\leq 57$ & 66 & 31 & 35 & $p=0.337$ \\
\hline & $>58$ & 65 & 36 & 29 & \\
\hline \multirow[t]{2}{*}{ Gender } & Male & 98 & 49 & 49 & $p=0.653$ \\
\hline & Female & 33 & 18 & 15 & \\
\hline \multirow[t]{3}{*}{ Tumor site } & Upper & 13 & 8 & 5 & $p=0.572$ \\
\hline & Middle & 104 & 51 & 53 & \\
\hline & lower & 14 & 8 & 6 & \\
\hline \multirow[t]{3}{*}{ Differentiation } & Poor & 12 & 10 & 2 & $p=0.074$ \\
\hline & Intermediate & 75 & 37 & 38 & \\
\hline & Well & 44 & 20 & 22 & \\
\hline \multirow[t]{2}{*}{ Tumor size } & $>5 \mathrm{~cm}$ & 82 & 48 & 34 & $p=0.029^{*}$ \\
\hline & $<5 \mathrm{~cm}$ & 49 & 19 & 30 & \\
\hline \multirow[t]{2}{*}{ Depth of invasion } & $\mathrm{T} 1-\mathrm{T} 2$ & 103 & 48 & 55 & $p=0.047^{*}$ \\
\hline & T3-T4 & 28 & 19 & 9 & \\
\hline \multirow[t]{2}{*}{ Lymph metastasis } & Yes & 68 & 32 & 36 & $p=0.286$ \\
\hline & No & 63 & 35 & 27 & \\
\hline \multirow[t]{4}{*}{ Clinical stage } & 1 & 6 & 4 & 2 & $p=0.257$ \\
\hline & 2 & 55 & 30 & 23 & \\
\hline & 3 & 64 & 32 & 32 & \\
\hline & 4 & 6 & 1 & 5 & \\
\hline
\end{tabular}

${ }^{*} \mathrm{p}<0.05$.

formation and cell invasion, as compared to cells transfected with the empty vector $(\mathrm{p}<0.001$ and $\mathrm{p}<0.05$ in both cell lines). As shown in Figure 4A, the occurrence of apoptosis was supported by the expression of cleaved caspase 3 in both cell lines. Correlating with these changes, there was a marked reduction in the expression levels of several anti-apoptotic proteins including BCL-2, BCL-xL and survivin. Furthermore, we also observed changes in two proteins known to regulate $G_{1}$ cell-cycle progression including $\mathrm{p} 21^{\mathrm{Waf} 1}$ and cyclin D1. Specifically, transfection of STAT1C into EC1 and
EC109 substantially upregulated p21 Waf1, a negative regulator of $\mathrm{G}_{1}$ cell-cycle progression [14]. Cyclin D1, a promoter of $G_{1}$ cell-cycle progression [15], was downregulated. Based on the results of the time-course experiment (Figure 4B), the decrease in the cyclin D1 protein level began as early as 6 hours after STAT1C gene transfection, indicating that the decrease in cyclin D1 was not due to the apoptotic activity. As shown in Figure $4 \mathrm{C}$, cell cycle analysis showed a significant increase in the sub- $G_{1}$ fractions in EC1 and EC109 cells transfected with STAT1C.

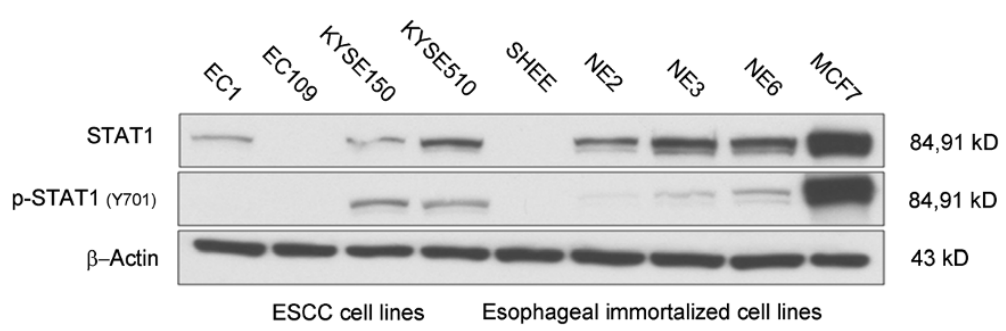

Figure 2 Expression of STAT1 and phospho-STAT1 in ESCC $(n=4)$ and esophageal immortalized cell lines $(n=4)$. ESCC cell lines included EC1, EC109, KYESE150 and KYSE510 and human esophageal immortalized cell lines included SHEE, NE2, NE3 and NE6. MCF7, a breast cancer cell line, served as a positive control. The expression of STAT1 was heterogeneous among these cell lines, and the expression of phospho-STAT1 was generally in parallel with the expression of STAT1. 


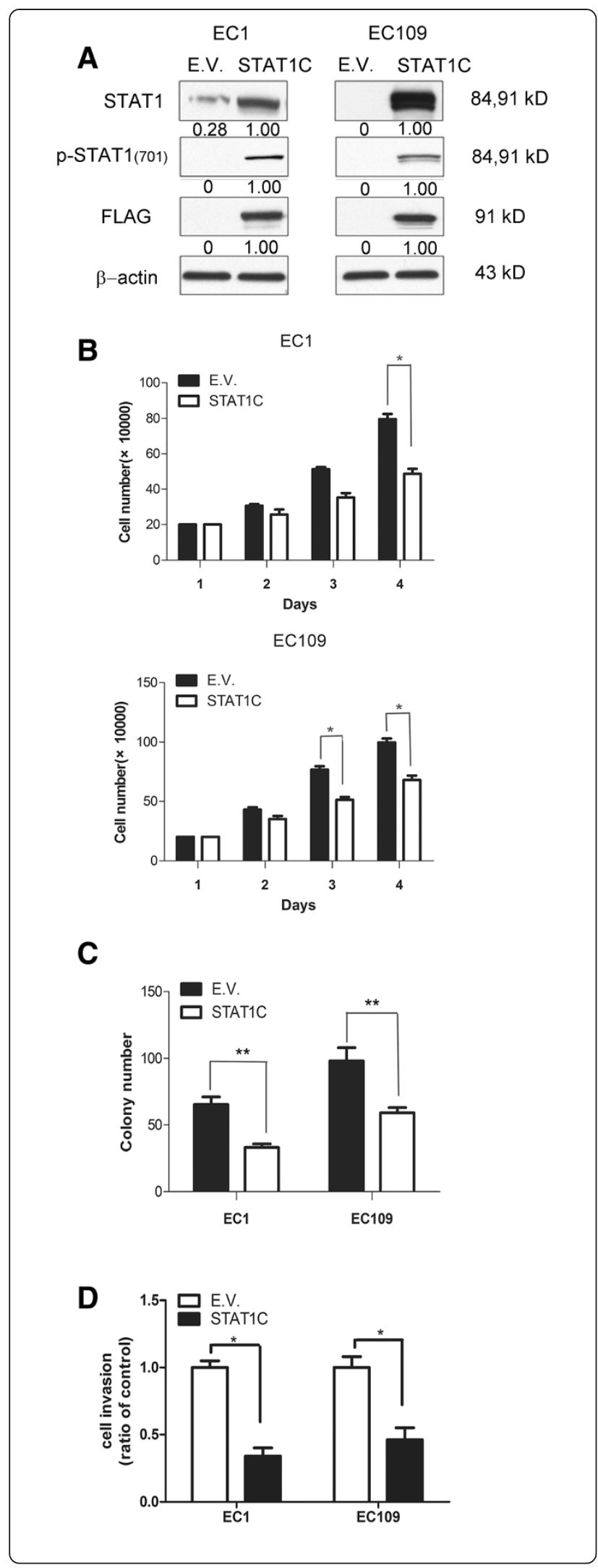

Figure 3 Gene transfection of STAT1C significantly decreases cell growth and tumorigenecity in ESCC cell lines. Using Western blot analysis, the gene transfection of STAT1C in EC1 and EC109 cells was shown to be effective, since the levels of STAT1, phospho-STAT1 and FLAG were dramatically increased 2 days after STATIC transfection (A). Cell growth, as assessed by trypan blue cell counting, was found to be significantly decreased after STAT1C transfection in EC1 and EC109 cells (B) $\left(^{*} \mathrm{p}<0.05\right)$. Tumorigenecity, assessed by using colony formation assay, was significantly lower in EC1 and EC109 cells transfected with STAT1C, as compared to cells transfected with an empty vector (C) (** $^{* *}$ $p<0.001)$. (D) Transwell invasion assay showed that the transfection of STAT1C significantly inhibited cell invasion both ESCC cell lines. Results shown are representative of three independent experiments. (E.V.: empty vector).

\section{The biological impact of siRNA knockdown of STAT1 in ESCC cell lines}

Next, the biological effects of siRNA knockdown of STAT1 in ESCC cells were evaluated. KYSE150 and KYSE510 cells, which showed the highest level of STAT1 expression among the 8 examined cell lines, were treated with STAT1 siRNA. As shown in Figure 5A and B, STAT1 siRNA induced a dramatic reduction in the STAT1 expression level in both cell lines. With this experimental system, we found that siRNA knockdown of STAT1 significantly decreased the number of viable cells, which was assessed by using the trypan blue exclusion assay $(\mathrm{p}<0.05$ for both cell lines) (Figure 5C). Furthermore, using colony formation assay, we found that siRNA knockdown of STAT1 of KYSE150 and KYSE510 induced a significant decrease in colony formation $(\mathrm{p}<0.0001, \mathrm{p}<0.0001$, respectively) (Figure 5D). As shown in Figure 5E, Western blot studies showed changes in the expression of $\mathrm{p} 21^{\text {waf1, }}$, cyclin D1, BCL-2 and BCL-xL in a pattern opposite to that seen in EC1 and EC109 cells transfected with STAT1C. As shown in Figure 5F, cell cycle analysis showed a significant decrease in the sub- $G_{1}$ fractions in KYSE150 and KYSE510 cells transfected with siRNA against STAT1, compared with the control.

\section{STAT1 inhibits NF-KB}

Previous studies have shown that STAT1 can block NF-kB by downregulating TNF- $\alpha$ [16]. In view of the importance of NF-kB in the biology of ESCC $[17,18]$, we hypothesized that the biological effects of STAT1C in ESCC may be mediated by down-regulating the NF- $\mathrm{kB}$ signaling. In keeping with this concept, we found that transfection of STAT1C into EC1 and EC109 cells resulted in a substantial decrease in the phosphorylation of NF-kB p65, a marker of NF- $k B$ activation [19] (Figure 6A). By subcellular fractionation, we also found that STAT1C transfection induced a dramatic decrease in the nuclear localization of NF- $\mathrm{KB}$ p65 or phospho-NF-kB p65 in both cell lines (Figure $6 \mathrm{~B}$ ). Lastly, we assessed the transcriptional activity of $N F-k B$ using a commercially available luciferase reporter construct. 


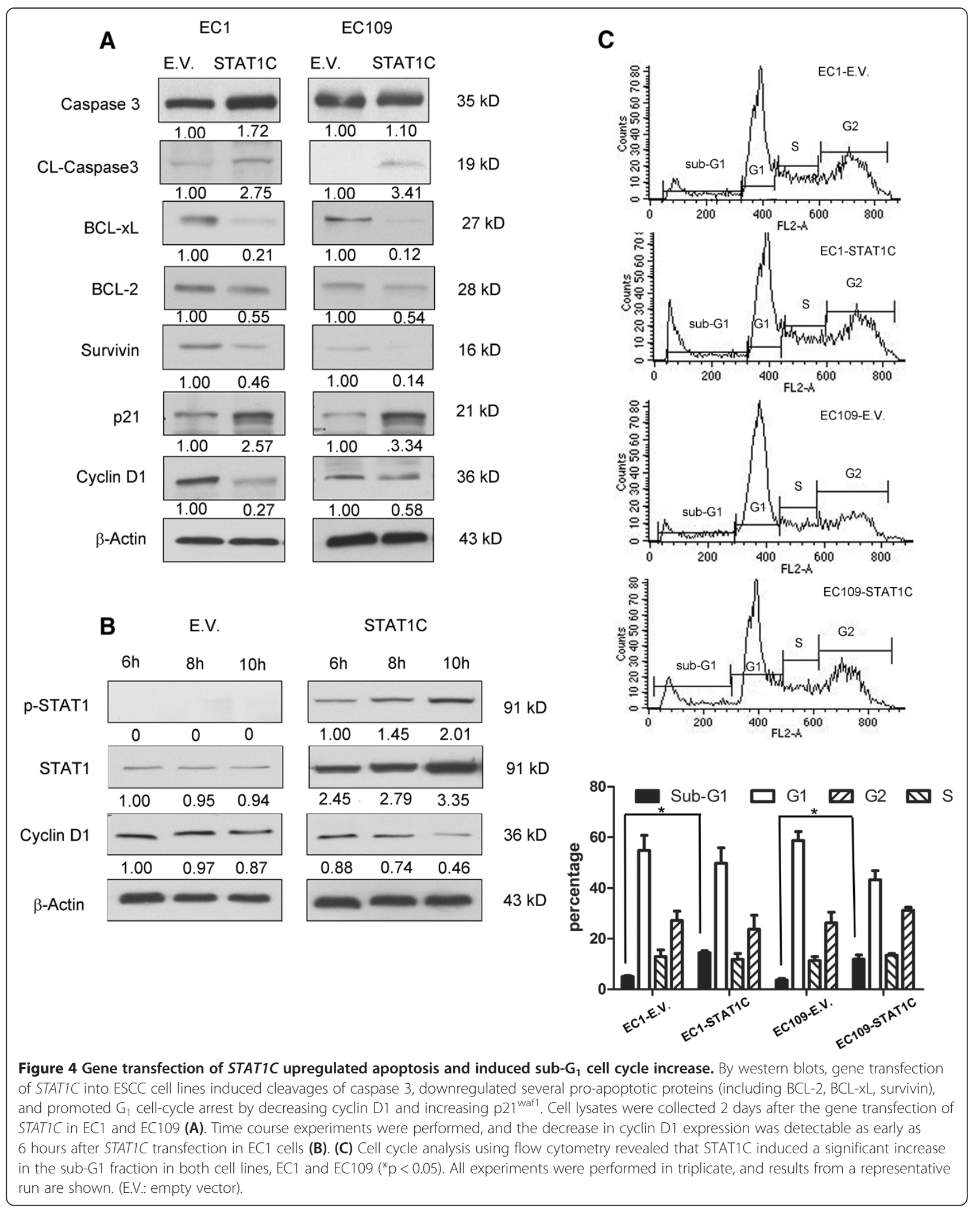




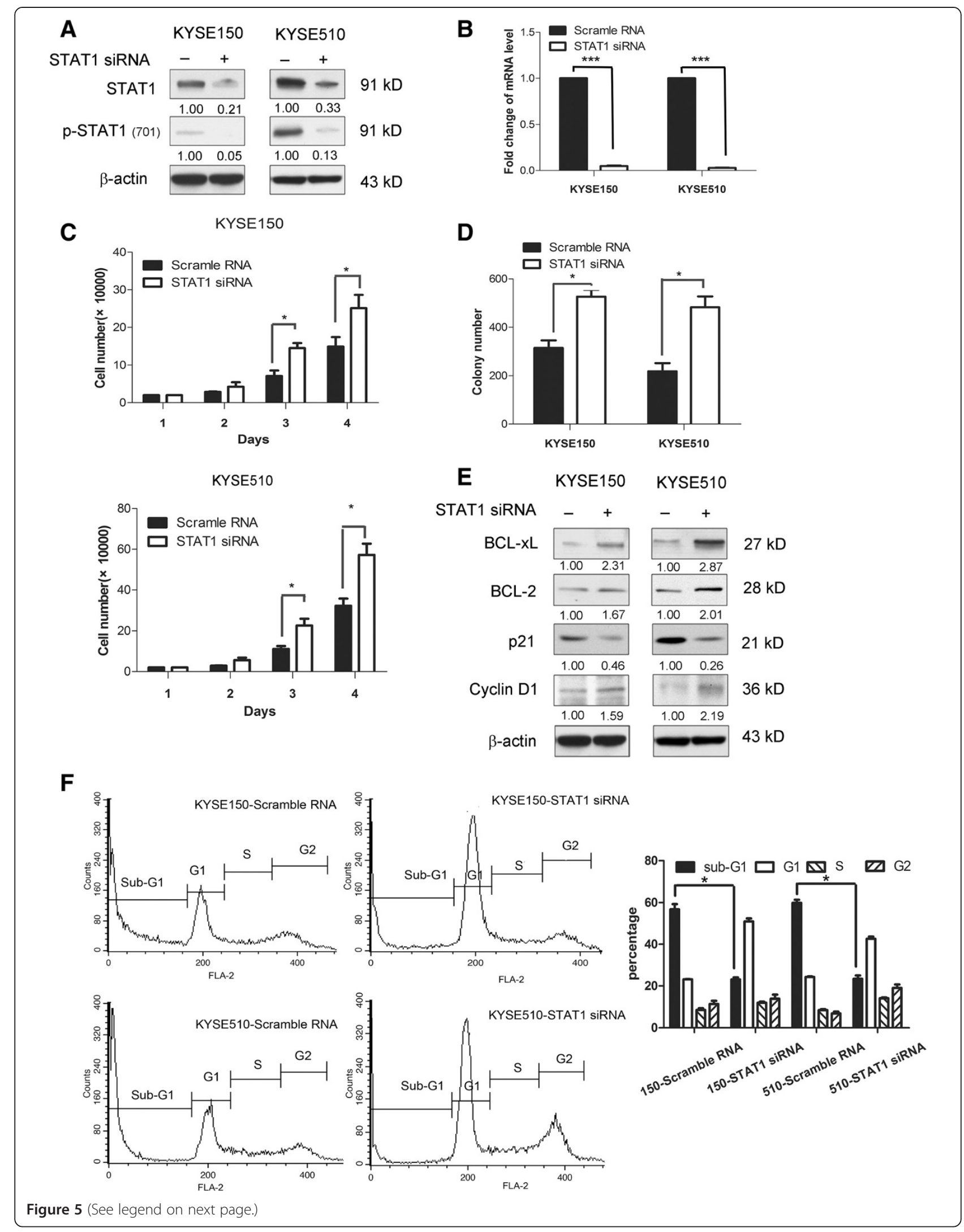


(See figure on previous page.)

Figure 5 Inhibition of STAT1 activation by siRNA. By Western blot analysis, the protein level of STAT1 and phospho-STAT1 were dramatically decreased in KYSE150 and KYSE510 treated with siRNA against STAT1. Cell lysates were collected 2 days after the siRNA transfection (A). The decrease in STAT1 expression after siRNA treatment was further supported by quantitative RT-PCR $\left(^{* * *} \mathrm{p}<0.0001\right)$ (B). In both KYSE150 and KYSE510, siRNA knockdown of STAT1 induced a significant decrease in cell growth, assessed by trypan blue eclusion assay. The cell numbers were assessed on day 4 after siRNA transfection. Triplicate experiments were performed and the results of a representative experiment are illustrated $\left({ }^{*} \mathrm{p}<0.05\right)$ (C). Transfection of STAT1 siRNA into KYSE150 and KYSE510 cells led to a significant reduction in the number of colonies formed, as compared to cells transfected with scrambled siRNA. Triplicate experiments were performed and the results of a representative experiment are shown $\left.{ }^{* * *} \mathrm{p}<0.0001\right)$ (D). By western blots, transfection of STAT1 siRNA resulted in an appreciable increase in BCL-XL, BCL-2, cyclin D1 and a corresponding decrease in p21 $1^{\text {waf1 }}$. Cells treated with scrambled siRNA served as the negative controls. Cell lysates were prepared two days after siRNA transfection (E). Cell cycle analysis using flow cytometry revealed that STAT1 siRNA induced a significant decrease in the sub-G1 fraction in both cell lines, KYSE150 and KYSE510 $\left.{ }^{*} \mathrm{p}<0.05\right)$. Results shown are representative of three independent experiments (F).

As shown in Figure 6C, there was a significant downregulation of NF-kB transcriptional activity after STAT1C transfection in both ESCC cells.

\section{STAT1C transfection downregulates STAT3 expression and activation}

Since STAT1 and STAT3 are known to counteract each other during their regulations of various cellular processes $[20,21]$, we asked if the modulation of STAT1 may have an impact on the expression and/or activation of STAT3. As shown in Figure 7A, we found that the expression levels for STAT3 and p-STAT3 were decreased 48 hours after STAT1C transfection into EC109 and EC1 cells. Correlating with these results, siRNA knockdown of STAT1 substantially increased the expression level of STAT3 and p-STAT3 in KYSE150 and KYSE510 (Figure 7A and B). We then assessed how STAT1C transfection might affect the physical interaction between STAT1 and STAT3 using co-immunoprecipitation. As shown in Figure 7C (right panel), by Western blots, transfection of STAT1C again resulted in 30-40\% reduction in the expression of STAT3. Co-immunoprecipitation studies (left panel) showed that transfection of STAT1C substantially increased the STAT3-STAT1 binding in both EC1 and EC109 cells. Considering that the total STAT3 protein level was decreased after STAT1C expression, these co-

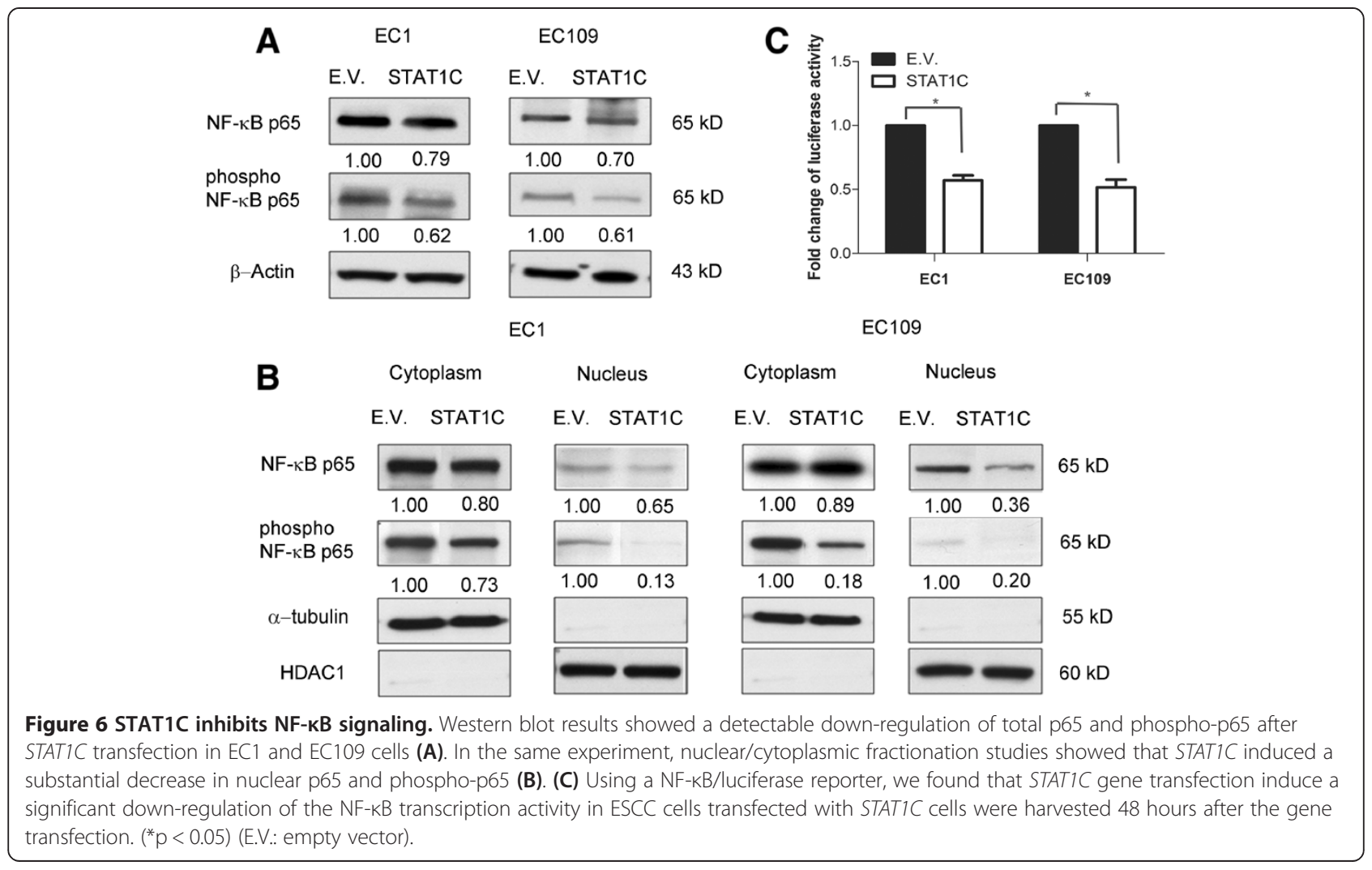




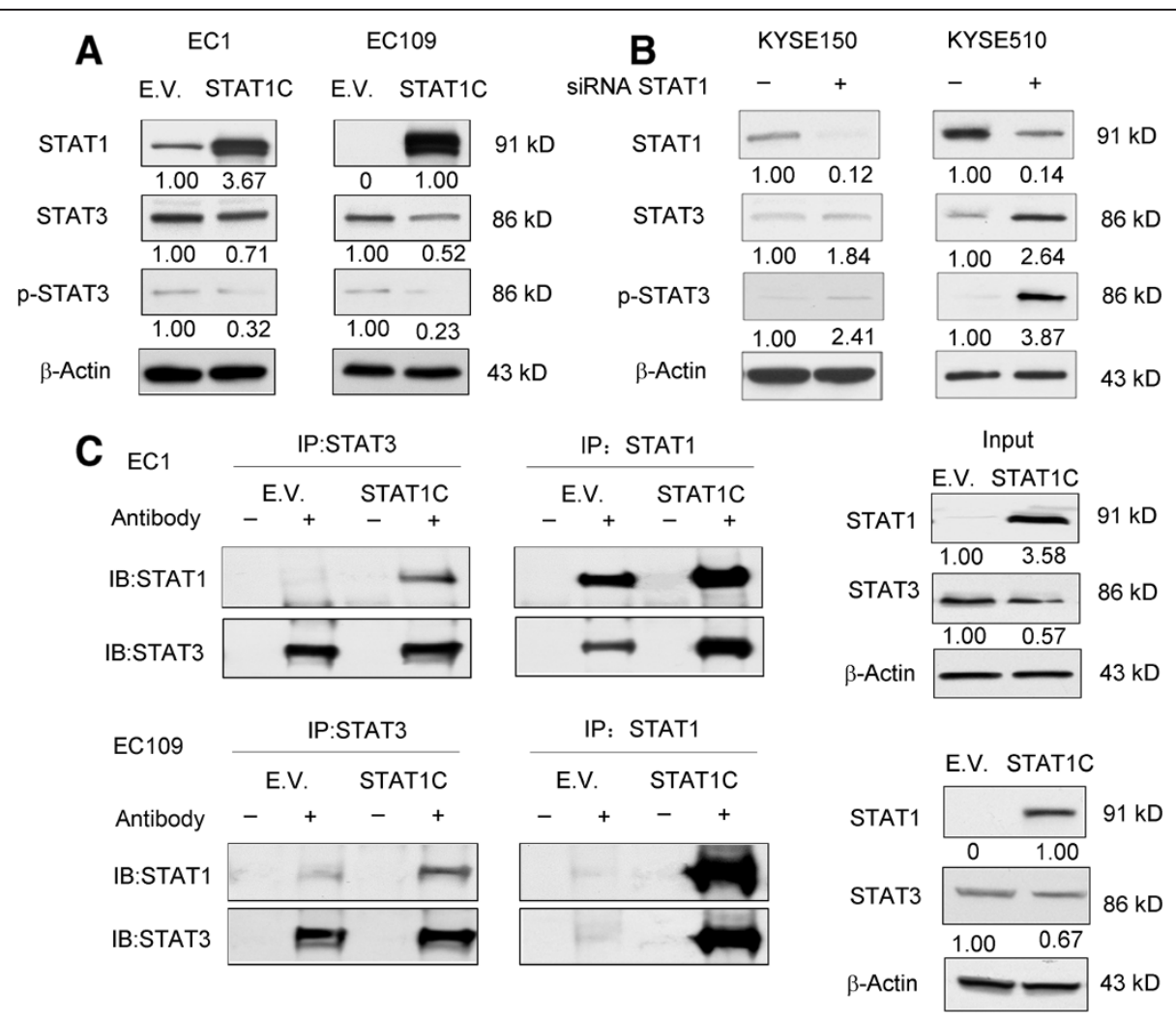

Figure 7 STAT1C decreases the expression level of STAT3 and phospho-STAT3 and increase STAT1-STAT3 heterodimer formation. Western blot studies showed that gene transfection of STAT1C induced an appreciable decrease in total STAT3 and phospho-STAT3 in EC1 and EC109 cells. Cell lysates were harvested 48 hours after gene transfection (A). In contrast, both STAT3 and phospho-STAT3 were increased in response to siRNA knockdown of STAT1 in KYSE150 and KYSE510 (B). Co-immunoprecipitation experiments revealed that gene transfection of STAT1C into EC1 and EC109 induced a substantial increase in STAT1:STAT3 heterodimer; at the same time, the total STAT3 protein level was decreased (C). Cell lysates were prepared 48 hours after gene transfection. (E.V.: empty vector).

immunoprecipitation data strongly support the concept that the STAT3 homodimers are decreased upon STAT1C transfection.

\section{Discussion}

STAT1 has been reported to regulate cellular differentiation and apoptosis through transcription-dependent as well as transcription-independent mechanisms [22]. There is also evidence that STAT1 carries tumor suppressor functions [23-25]. Decreased or loss of STAT1 expression has been observed in many cancer types such as breast cancer, melanoma and leukemia [2,26-28]; transfection of STAT1 or STAT1C into cancer cells can arrest their growth by inducing apoptosis and cell-cycle arrest $[1,9,29]$. STAT1 appears to exert its tumor suppressor functions via multiple mechanisms, including downregulation of caspases, Fas, FasL, TRAIL and p21 ${ }^{\text {waf1 }}$ [22]. The apoptosis-inducing function of STAT1 also has been linked to its inhibition of IFN- $\gamma$ signaling and the subsequent downregulation of several proapoptotic proteins including Bak and Bax [2]. Despite the fact that the tumor suppressor function of STAT1 is increasingly recognized, the significance of STAT1 in ESCC has not been clearly defined.

One of the key findings of this study is that the absence of STAT1 expression in ESCC significantly correlates with a worse clinical outcome. Of note, we would like to acknowledge that this observation was based on a comparison between 8 STAT1-negative and 66 STAT1-strong/ weak tumors. This highly skewed pattern may have introduced some biases; thus, larger studies using other patient cohorts are needed to confirm this finding. Nonetheless, we do believe that STAT1 holds prognostic value, since we found prognostic significance when we compared STAT1-weak/negative cases and STAT1-strong cases in the cohort of poorly or intermediate-differentiated tumors (Figure 1C). Furthermore, STAT1 expression was also found to correlate with the depth of tumor invasion and tumor size. In this regard, tumor size is one of the determinants of the TNM clinical staging system for ESCC patients [30,31]. To our knowledge, the prognostic significance of STAT1 in ESCC has never been previously described. Nevertheless, we are aware of a relatively small number of published studies that had found prognostic 
significance of STAT1 in other types of cancer, such as gastric cancer and melanoma [26,32].

Correlating with our clinical observations, our in-vitro studies have provided further support that STAT1 carries tumor suppressor functions in ESCC. Specifically, we found that transfection of STAT1C into ESCC induced apoptosis and cell-cycle arrest, with the effect on apoptosis being more pronounced than that on cell proliferation (Figures 3 and 4). On the other hand, siRNA knock-down of STAT1 in ESCC cells results in opposite effects. In parallel to our findings, we have identified two in-vitro studies in the literature that may have implicated a role of STAT1 in the biology of ESCC $[9,33]$. In one of these two studies, IFN- $\gamma$ and EGF were found to induce apoptosis in KYSE 70 and KYSE 590, two ESCC cell lines [9]. However, while the apoptosis induced by both cytokines was found to correlate with STAT1 activation, whether STAT1 activation is directly responsible for the occurrence of apoptosis in these cells was not clear. In this current study, the use of STAT1C and STAT1 siRNA allowed us to pinpoint STAT1 as a key mediator of the induction of apoptosis and cell-cycle arrest in ESCC.

We attempted to delineate the mechanisms by which STAT1 induces apoptosis in ESCC. We found that some of the mechanisms are similar to those previously reported for other cancer types [34]. Thus, gene transfection of STAT1C in fibrosarcoma cell lines was found to induce caspase activation and caspase-dependent apoptosis [13]. As we found that STAT1C-induced apoptosis in ESCC correlates with the down-regulation of several pro-survival proteins such as BCL-2 and BCL-xL, previous studies also have shown that STAT1 can promote apoptosis by down-regulating $\mathrm{BCL}-2$ and $\mathrm{BCL}-\mathrm{xL}$ in multiple myelomas [29].

We also have found evidence that STAT1 can modulate the expression of $\mathrm{G}_{1}$ cell-cycle regulatory proteins such as $\mathrm{p} 21^{\text {waf1 }}$ and cyclin D1 in ESCC. Upregulation of cyclin D1 has been shown to shorten the $G_{1}$ phase and reported to link to the development and progression of many types of cancer, such as breast cancer [35], gastric cancer [36] and mantle cell lymphoma [37]. In ESCC, cyclin D1 expression detectable by $\mathrm{IHC}$ is associated with a worse prognosis [38,39]. Thus, down-regulation of cyclin D1 induced by STAT1 may partly explain our observation that high STAT1 expression in ESCC is associated with a better clinical outcome. As shown in Figure $4 \mathrm{~B}$, our observation that the down-regulation of cyclin D1 occurred as early as 6 hours after STAT1C gene transfection suggests that this biochemical change was a consequence of STAT1 up-regulation, rather than a 'by-product' of apoptosis.

In various cancer cell types, STAT1 has been previously reported to be an important mediator for NF- $\mathrm{kB}$, which is known to play a critical role in carcinogenesis and chemoresistance in ESCC [40,41]. The NF-кB signaling pathway was found to be constitutively activated in many ESCC cell lines; down-regulation of p65 has been shown to increase the sensitivity of ESCC cells to chemotherapeutic drugs $[17,18]$. With this background, we tested if STAT1 is functionally linked to NF-kB in our experimental model. Our findings that modulation of STAT1 expression changed the expression level of phospho-p65, as well as the nuclear localization of p65/ phospho-p65, and these findings support the concept that the STAT1 inhibits the growth of ESCC via its suppression of NF-kB signaling. Similar results have been described in cervical cancer, melanomas and fibrosarcomas [16,42-44].

STAT3, another member of the STAT family, has been shown to exert opposing biological effects of STAT1 $[20,21,45]$. In contrast with STAT1, STAT3 promotes survival, proliferation and motility of cancer cells, and induces immune tolerance [46]. Some of these opposing biological effects are likely related to the cross-talk between STAT1 and STAT3. For instance, it has been shown that STAT3 can block the activation and function of STAT1 in human monocytic cells [47]. STAT3knockout mouse embryonic fibroblasts exhibited prolonged IL-6-mediated STAT1 activation and induction of IFN- $\gamma$-inducible genes [48]. In this study, we found evidence that STAT1 interferes with STAT3 signaling in ESCC cells using at least two mechanisms. First, STAT1 down-regulates STAT3 as well as phospho-STAT3. To our knowledge, this is a novel finding. Second, coimmunoprecipitation studies showed that STAT1C transfection in ESCC cells substantially increased STAT1: STAT3 heterodimer. Since the total STAT3 protein level was decreased after STAT1C transfection, it is logical to assume that STAT3:STAT3 homodimers were dramatically decreased at the same time. We believe that these findings are linked to the tumor suppressive effects of STAT1C in ESCC, as previous studies have shown that the relative proportions of STAT1 homodimers, STAT3 homodimers and STAT1:STAT3 heterodimers dictate the cell fate $[21,49,50]$. Based on the literature, other mechanisms where STAT1 inhibits STAT3 signaling may also exist. For instance, it has been shown that STAT1 can compete with STAT3 for the common receptor docking sites or target DNA sequences $[2,20]$. Of note, most of these STAT1-mediated effects on STAT3 take place in the cytoplasm, and this may correlate with our observation that cytoplasmic STAT1, rather than nuclear STAT1, was prognostically important.

The role of STAT1 as a tumor suppressor is not without controversy. STAT1 overexpression has been demonstrated in several types of human cancer [51-55]. Some reports also have demonstrated that constitutive STAT1 
signaling promotes tumor growth, increases resistance to chemotherapy and radiation, and carries a worse clinical outcome in patients with glioblastoma multiforme [56]. The possible explanations for these rather contradictory findings may be related to the biological heterogeneity of cancer and STAT1 may function as a tumor suppressor or oncoprotein in a cell-type specific manner.

\section{Conclusion}

In conclusion, our findings suggest that STAT1 is a tumor suppressor in ESCC. Loss of STAT1, which is frequent in ESCC, contributes to the pathogenesis of these tumors. We have provided evidence that STAT1 attenuates the tumorigenicity of ESCC by inhibiting the STAT3 and NF$\mathrm{KB}$ signaling pathway, and therefore that activation of STAT1 may be a useful approach to treat ESCC.

\section{Competing interests}

The authors declare that they have no competing interests.

\section{Authors' contributions}

$Y Z$, MS and RL designed and carried out experiments, and $Y Z$ and $R L$ designed experiments and analyzed data. YZ and OM carried out experiments. All authors were involved in writing the paper and had final approval of the submitted and published versions.

\section{Acknowledgements}

We thank the Professor Liyan Xu at the Shantou University Medical College for sharing SHEE, KYSE150 and KYSE510 cells with us. We also would like to thank Professor George Tsao from the University of Hong Kong for sharing NE2, NE3 and NE6 with us. ZY is a graduate student supported by the Li Ka Shing funding scholarship administered by the University of Alberta. This study was supported by NSFC-Guangdong joint fund key project (Certificates U1132004), NSFC (Certificates 31171226), Guangdong International Cooperative Technical Innovation Platform(Certificates gihz1106) and an operating research grant from the Canadian Institute of Health Research awarded to RL.

\section{Author details \\ ${ }^{1}$ Department of Pathology, Shantou University Medical College, 22 Xinling Road, Shantou 515031, Guangdong Province, China. ${ }^{2}$ Department of Laboratory Medicine and Pathology, University of Alberta, Edmonton, Alberta, Canada. ${ }^{3}$ Department of Oncology, University of Alberta, Edmonton, Alberta, Canada. ${ }^{4}$ DynaLIFEDX Medical Laboratories, Edmonton, Alberta, Canada. ${ }^{5}$ Department of Laboratory Medicine and Pathology, University of Alberta, 5142 Katz Group Centre for Pharmacy and Health Research, Edmonton, Alberta T6G 2E1, Canada.}

Received: 14 July 2014 Accepted: 13 October 2014 Published: 29 October 2014

\section{References}

1. Li J, Yu B, Song L, Eschrich S, Haura EB: Effects of IFN-gamma and Stat1 on gene expression, growth, and survival in non-small cell lung cancer cells. J Interferon Cytokine Res 2007, 27(3):209-220.

2. Adámková L, Soucková K, Kovarík J: Transcription protein STAT1: biology and relation to cancer. Folia Biol (Praha) 2007, 53(1):1-6.

3. Calò V, Migliavacca M, Bazan V, Macaluso M, Macaluso M, Buscemi M, Gebbia N, Russo A: STAT proteins: from normal control of cellular events to tumorigenesis. J Cell Physiol 2003, 197:157-168.

4. Battle TE, Frank DA: The role of STATs in apoptosis. Curr Mol Med 2002, 2:381-392.

5. Max Parkin D, Bray F, Ferlay J, Pisani P: Global cancer statistics, 2002 CA cancer. J Clin 2002, 2005(55):74-108.

6. Su M, Liu M, Tian DP, Li XY, Zhang GH, Yang HL, Fan X, Huang HH, Gao YX: Temporal trends of esophageal cancer during 1995-2004 in Nanao
Island, an extremely high-risk area in China. Eur J Epidemiol 2007, 22(1):43-48.

7. Zhang $H Z$, Jin GF, Shen HB: Epidemiologic differences in esophageal cancer between Asian and Western populations. Chin J Cancer 2012, 31(6):281-286.

8. Polednak AP: Trends in survival for both histologic types of esophageal cancer in US surveillance, epidemiology and end results areas. Int $J$ Cancer 2003, 105(1):98-100

9. Kaganoi J, Watanabe G, Okabe M, Nagatani S, Kawabe A, Shimada Y, Imamura M, Sakai Y: STAT1 activation-induced apoptosis of esophageal squamous cell carcinoma cells in vivo. Ann Surg Oncol 2007, 14(4):1405-1415.

10. Watanabe G, Kaganoi J, Imamura M, Shimada Y, Itami A, Uchida S, Sato F, Kitagawa M: Progression of esophageal carcinoma by loss of EGF-STAT1 pathway. Cancer J 2001, 7(2):132-139.

11. Armanious H, Gelebart P, Mackey J, Ma Y, Lai R: STAT3 upregulates the protein expression and transcriptional activity of beta-catenin in breast cancer. Int J Clin Exp Pathol 2010, 3(7):654-664

12. Armanious $H$, Gelebart $P$, Anand $M$, Belch A, Lai R: Constitutive activation of metalloproteinase ADAM10 in mantle cell lymphoma promotes cell growth and activates the TNFa/NFkB pathway. Blood 2011, 117(23):6237-6246.

13. Sironi JJ, Ouchi T: STAT1-induced apoptosis is mediated by caspases 2, 3, and 7. J. Biol Chem 2004, 279(6):4066-4074.

14. Abbas T, Dutta A: p21 in cancer: intricate networks and multiple activities. Nat Rev Cancer 2009, 9(6):400-414.

15. Dimco G, Knight RA, Latchman DS, Stephanou A: STAT1 interacts directly with cyclin D1/Cdk4 and mediates cell cycle arrest. Cell Cycle 2010, 9:4638-4649.

16. Suk K, Chang I, Kim YH, Kim S, Kim JY, Kim H, Lee MS: Interferon gamma (IFN gamma) and tumor necrosis factor alpha synergism in ME-180 cervical cancer cell apoptosis and necrosis. J Biol Chem 2001, 276(16):13153-13159.

17. Tian F, Zang WD, Hou WH, Liu HT, Xue LX: Nuclear factor-kB signaling pathway constitutively activated in esophageal squamous cell carcinoma cell lines and inhibition of growth of cells by small interfering RNA. Acta Biochim Biophys Sin (Shanghai) 2006, 38(5):318-326.

18. Tian F, Zhang C, Tian W, Jiang Y, Zhang X: Comparison of the effect of p65 siRNA and curcumin in promoting apoptosis in esophageal squamous cell carcinoma cells and in nude mice. Oncol Rep 2012, 28(1):232-240

19. Kienan V, Brec V, Ng W, Coudart MP, El Messaoudi S, Sardet C, Jin DY, Emiliani S, Benkirane M: Post-activation turn-off of NF-kappa B-dependent transcription is regulated by acetylation of p65. J. Biol. Chem 2003, 278:2758-2766.

20. Qing Y, Stark GR: Alternative activation of STAT1 and STAT3 in response to interferon-gamma. J Biol Chem 2004, 279(40):41679-41685.

21. Pensa S, Regis G, Boselli D, Novelli F, Valeria Poli: STAT1 and STAT3 in Tumorigenesis: Two Sides of the Same Coin? In JAK-STAT Pathway in Disease. Edited by Anastasis Stephanou. 2009:100-113.

22. Kim HS, Lee MS: STAT1 as a key modulator of cell death. Cell Signal 2007, 19(3):454-465.

23. Durbin JE, Hackenmiller R, Simon MC, Levy DE: Targeted disruption of the mouse Stat 1 gene results in compromised innate immunity to viral disease. Cell 1996, 84(3):443-450.

24. Lee CK, Rao DT, Gertner R, Gimeno R, Frey AB, Levy DE: Distinct requirements for IFNs and STAT1 in NK cell function. J Immunol 2000, 165(7):3571-3577.

25. Lee CK, Smith E, Gimeno R, Gertner R, Levy DE: STAT1 affects lymphocyte survival and proliferation partially independent of its role downstream of IFN-gamma. J Immunol 2000, 164(3):1286-1292.

26. Deng H, Zhen H, Fu Z, Huang X, Zhou H, Liu L: The antagonistic effect between STAT1 and Survivin and its clinical significance in gastric cancer. Oncol Lett 2012, 3(1):193-199.

27. Kovarik J, Boudny V, Kocak I, Lauerova L, Fait V, Vagundova M: Malignant melanoma associates with deficient IFN-induced STAT 1 phosphorylation. Int J Mol Med 2003, 12:335-340.

28. Bowman T, Garcia R, Turkson J, Jove R: STATs in oncogenesis. Oncogene 2000, 19:2474-2488.

29. Dimberg LY, Dimberg A, Ivarsson K, Fryknäs M, Rickardson L, Tobin G, Ekman S, Larsson R, Gullberg U, Nilsson K, Öberg F, Wiklund HJ: Stat1 
activation attenuates IL-6 induced Stat3 activity but does not alter apoptosis sensitivity in multiple myeloma. BMC Cancer 2012, 12:318.

30. Wang BY, Goan YG, Hsu PK, Hsu WH, Wu YC: Tumor length as a prognostic factor in esophageal squamous cell carcinoma. Ann Thorac Surg 2011, 91:887-893.

31. Wang Z: The Invasion, Lymphatic Metastasis and Prognostic in ESCC. In Master thesis. Guangxi Medical College; 2011.

32. Meyer S, Wild PJ, Vogt T, Bataille F, Ehret C, Gantner S, Landthaler M Klinkhammer-Schalke M, Hofstaedter F, Bosserhoff AK: Methylthioadenosine phosphorylase represents a predictive marker for response to adjuvant interferon therapy in patients with malignant melanoma. Exp Dermatol 2010, 19(8):e251-e257.

33. Ichiba M, Miyazaki Y, Kitamura S, Kiyohara T, Shinomura Y, Matsuzawa Y: Epidermal growth factor inhibits the growth of TE8 esophageal cancer cells through the activation of STAT1. J Gastroenterol 2002, 37(7):497-503.

34. Sasagawa T, Hlaing M, Akaike T: Synergistic induction of apoptosis in murine hepatoma Hepa1-6 cells by IFN-gamma and TNF-alpha. Biochem Biophys Res Commun 2000, 272(3):674-680.

35. Sutherland RL, Musgrove EA: Cyclin D1 and mammary carcinoma: new insights from transgenic mouse models. Breast Cancer Res 2002, 4:14-17.

36. Zheng L, Qi T, Yang D, Qi M, Li D, Xiang X, Huang K, Tong Q: MicroRNA-9 suppresses the proliferation, invasion and metastasis of gastric cancer cells through targeting cyclin D1 and Ets1. PLoS One 2013, 8(1):55719.

37. Campo E, Raffeld M, Jaffe ES: Mantle-cell lymphoma. Semin Hematol 1999, 36(2):115-127.

38. Inomata M, Uchino S, Tanimura $H$, Shiraishi $N$, Adachi $Y$, Kitano S: Amplification and overexpression of cyclin D1 in aggressive human esophageal cancer. Oncol Rep 1998, 5(1):171-176.

39. Zhao J, Li L, Wei S, Gao Y, Chen Y, Wang G, Wu Z: Clinicopathological and prognostic role of cyclin D1 in esophageal squamous cell carcinoma: a meta- analysis. Dis Esophagus 2012, 25(6):520-526.

40. Abdel-Latif MM, O'Riordan J, Windle HJ, Carton E, Ravi N, Kelleher D, Reynolds JV: NF-KB activation in esophageal adenocarcinoma: relationship to Barrett's metaplasia, survival, and response to neoadjuvant chemoradiotherapy. Ann Surg 2004, 239(4):491-500.

41. Su C, Chen Z, Luo H, Su Y, Liu W, Cai L, Wang T, Lei Y, Zhong B: Different patterns of NF-KB and Notch1 signaling contribute to tumor-induced lymphangiogenesis of esophageal squamous cell carcinoma. J Exp Clin Cancer Res 2011, 30:85.

42. Krämer $\mathrm{OH}$, Baus D, Knauer SK, Stein S, Jäger E, Stauber RH, Grez M, Pfitzner E, Heinzel T: Acetylation of Stat1 modulates NF-kappaB activity. Genes Dev 2006, 20(4):473-485.

43. Wang Y, Wu TR, Cai S, Welte T, Chin YE: Stat1 as a component of tumor necrosis factor alpha receptor 1-TRADD signaling complex to inhibit NFkappaB activation. Mol Cell Biol 2000, 20(13):4505-4512.

44. Gelebart P, Zak Z, Anand M, Dien-Bard J, Amin HM, Lai R: Interleukin-21 effectively induces apoptosis in mantle cell lymphoma through a STAT1dependent mechanism. Leukemia 2009, 23(10):1836-1846.

45. Zhang Y, Du XL, Wang CJ, Lin DC, Ruan X, Feng YB, Huo YQ, Peng H, Cui JL, Zhang TT, Wang YQ, Zhang H, Zhan QM, Wang MR: Reciprocal activation between PLK1 and Stat3 contributes to survival and proliferation of esophageal cancer cells. Gastroenterology 2012, 142(3):521-530.

46. Sakamoto C: STAT1 and STAT3 might be regulated differently in esophageal squamous cell carcinoma. J Gastroenterol 2002, 37(7):575-577.

47. Ho HH, Ivashkiv LB: Role of STAT3 in type I interferon responses. Negative regulation of STAT1-dependent inflammatory gene activation. J Biol Chem 2006, 281(20):14111-14118.

48. Costa-Pereira AP, Tininini S, Strobl B, Alonzi T, Schlaak JF, Is'harc H, Gesualdo I, Newman SJ, Kerr IM, Poli V: Mutational switch of an IL-6 response to an interferon-gamma-like response. Proc Natl Acad Sci USA 2002, 99(12):8043-8047.

49. Regis G, Pensa S, Boselli D, Novelli F, Poli V: Ups and downs: the STAT1: STAT3 seesaw of Interferon and gp130 receptor signalling. Semin Cell Dev Biol 2008, 19(4):351-359.

50. Thyrell L, Arulampalam V, Hjortsberg L, Farnebo M, Grandér D, Pokrovskaja Tamm K: Interferon alpha induces cell death through interference with interleukin 6 signaling and inhibition of STAT3 activity. Exp Cell Res 2007, 313(19):4015-4024.

51. Khodarev NN, Beckett M, Labay E, Darga T, Roizman B, Weichselbaum RR: STAT1 is overexpressed in tumors eslected for radioresistance and confers protection from radiation in transduced sensitive cells. Proc Natl Acad Sci USA 2004, 101(6):1714-1719.
52. Buettner R, Mora LB, Jove R: Activated STAT signaling in human tumors provides novel molecular targets for therapeutic intervention. Clin Cancer Res 2002, 8(4):945-954

53. Perou CM, Sorlie T, Eisen MB, van de Rijn M, Jeffrey SS, Rees CA, Pollack JR, Ross DT, Johnsen H, Akslen LA, Fluge O, Pergamenschikov A, Williams C, Zhu SX, Lønning PE, Børresen-Dale AL, Brown PO, Botstein D: Molecular portraits of human breast tumours. Nature 2000, 406:747-752.

54. Greenwood C, Metodieva G, Al-Janabi K, Lausen B, Alldridge L, Leng L, Bucala R, Fernandez N, Metodiev MV: STAT1 and CD74 overexpression is codependent and linked to increase invasion and lymph node metastasisintriplenegative breast cancer. J Proteomics 2012, 75(10):3031-3040.

55. Yao R, Wang Y, Lubet RA, You M: Differentially expressed genes associated with mouse lung tumor progression. Oncogene 2002 21(37):5814-5821.

56. Duarte CW, Willey CD, Zhi D, Cui X, Harris JJ, Vaughan LK, Mehta T, McCubrey RO, Khodarev NN, Weichselbaum RR, Gillespie GY: Expression signature of IFN/STAT1 signaling genes predicts poor survival outcome in glioblastoma multiforme in a subtype-specific manner. PLoS One 2012, 7(1):e29653.

doi:10.1186/1471-2407-14-791

Cite this article as: Zhang et al.: The clinical and biological significance of STAT1 in esophageal squamous cell carcinoma. BMC Cancer 2014 14:791.

\section{Submit your next manuscript to BioMed Central and take full advantage of:}

- Convenient online submission

- Thorough peer review

- No space constraints or color figure charges

- Immediate publication on acceptance

- Inclusion in PubMed, CAS, Scopus and Google Scholar

- Research which is freely available for redistribution

Submit your manuscript at www.biomedcentral.com/submit
C) BioMed Central 